Hui-Ju Chen · Shuan-Pei Lin · Hung-Chang Lee

Chih-Ping Chen · Nan-Chang Chiu · Han-Yang Hung

Schu-Rern Chern $\cdot$ Chih-Kuang Chuang

\title{
Cystic fibrosis with homozygous R553X mutation in a Taiwanese child
}

Received: 23 August 2005/ Accepted: 26 August 2005/Published online: 10 November 2005

(C) The Japan Society of Human Genetics and Springer-Verlag 2005

\begin{abstract}
It has been reported that cystic fibrosis is very rare in Asians, and its clinical expression and genetic mutations are different from those found in Caucasians. We report the case of a boy who had chronic diarrhea with failure to thrive and frequent respiratory tract infections beginning at the age of 2 months. He developed bronchiectasis with chronic severe hypoxemia and pancreatic insufficiency by the age of 3 years and 5 months, which raised the consideration of cystic fibrosis. DNA analysis revealed a homozygous R553X mutation, and both his parents were subsequently proven to be R553X carriers. This case is the first report in a Taiwanese with cystic fibrosis attributable to a mutation commonly seen in Caucasians. However, the age of onset was much younger and the clinical course was more severe than those associated with Western patients. We reviewed the eight reported Taiwanese patients with
\end{abstract}

H.-J. Chen · S.-P. Lin $(\bowtie) \cdot$ H.-C. Lee $\cdot$ N.-C. Chiu $\cdot$ H.-Y. Hung Division of Genetics, Department of Pediatrics, Mackay Memorial Hospital, 92, Section 2, Chung-Shan North Road, 10449 Taipei, Taiwan

E-mail: zsplin@ms2.mmh.org.tw

Tel.: + 886-2-25433535

Fax: + 886-2-25433642

S.-P. Lin · C.-P. Chen · S.-R. Chern · C.-K. Chuang

Department of Medical Research, Mackay Memorial Hospital, Taipei, Taiwan

C.-P. Chen

Department of Obstetrics and Gynecology, Mackay Memorial Hospital, Taipei, Taiwan

S.-P. Lin · N.-C. Chiu

Mackay Medicine, Nursing and Management College, Taipei, Taiwan

S.-P. Lin

Department of Clinical Pathology, Taipei Institute of Pathology, Taipei, Taiwan

H.-C. Lee

Department of Pediatrics, Taipei Medical University, Taipei, Taiwan cystic fibrosis, including the present case. We believe that the incidence of cystic fibrosis in Taiwan may be underestimated. Both genetic and environmental factors may play a role in the phenotypic disparity between Asians and Caucasians.

Key words Cystic fibrosis - Homozygous R553X

Taiwan - Cystic fibrosis transmembrane receptor

\section{Introduction}

Cystic fibrosis is an autosomal recessive inherited disorder most commonly found in Caucasians, with an incidence of one in 2,000 newborns (Anonymous 1976). The disease is very rare, however, in Asian populations. One study in Hawaii revealed an incidence of less than one in 90,000 live births among Asians (Wright and Morton 1968), and another study from Japan suggested that the incidence is about one in 350,000 in the Japanese population (Yamashiro et al. 1997). Some studies have demonstrated that the genotype and phenotype in Asians with cystic fibrosis are quite different than those seen in Western populations (Macek et al. 1992; Bowler et al. 1993; Zielenski et al. 1995; Suwanjutha et al. 1998; Wagner et al. 1999; Morokawa et al. 2000; Heim et al. 2001; Wong et al. 2003; Ahn et al. 2005). To date, only seven patients with cystic fibrosis (from six different families) have been reported in Taiwan, five with novel cystic fibrosis transmembrane receptor (CFTR) mutations (Wang et al. 1987, 1993; Zielenski et al. 1995; Wu et al. 2000; Alper et al. 2003; Wong et al. 2003). We report a 3-year-5-month-old boy born to Taiwanese parents with classical clinical manifestations of cystic fibrosis and who has a homozygous R553X mutation of the CFTR gene. To our knowledge, this is only the eighth patient with cystic fibrosis reported in Taiwan, and he is the only one who carries the CFTR gene mutation commonly seen in Caucasians. 
However, even with the similar genotype, his clinical presentation was more severe than that reported in Western patients.

\section{Case report}

A 3-year-5-month-old child was admitted to our hospital with complaints of dyspnea, productive cough, and fever up to $38.8^{\circ} \mathrm{C}$ for 5 days prior to admission. He was the first child of unrelated, healthy, native Taiwanese parents from the southern part of the island. The birth and family history were unremarkable, as was his feeding history. He had had chronic diarrhea and frequent respiratory tract infections since the age of 2 months. He had been admitted to our hospital at 4 months of age with failure to thrive and severe dehydration with hyponatremia, hypokalemia, and hypochloremic metabolic alkalosis. However, no definitive diagnosis was made at that time. Bartter syndrome was ruled out, as he had a low urine chloride level and no other laboratory results consistent with it. Mild steatorrhea was noted, but the stool trypsin level was not decreased. After the symptoms were corrected, he was discharged and was lost to follow-up. His parents stated that he developed rectal prolapse at the age of 3 years.

On admission, he looked listless and malnourished. His weight was $8.5 \mathrm{~kg}$ and height $87 \mathrm{~cm}$, both below the third percentile. His psychomotor development was within normal limits. The thoracic cage was barrelshaped, and there were significant subcostal and intercostal retractions. Chest auscultation revealed diffuse wheezing and crackles in both lung fields. The abdomen was distended and tympanic on percussion. The liver was palpable $2 \mathrm{~cm}$ below the right costal margin. The muscles in all four extremities were wasted.

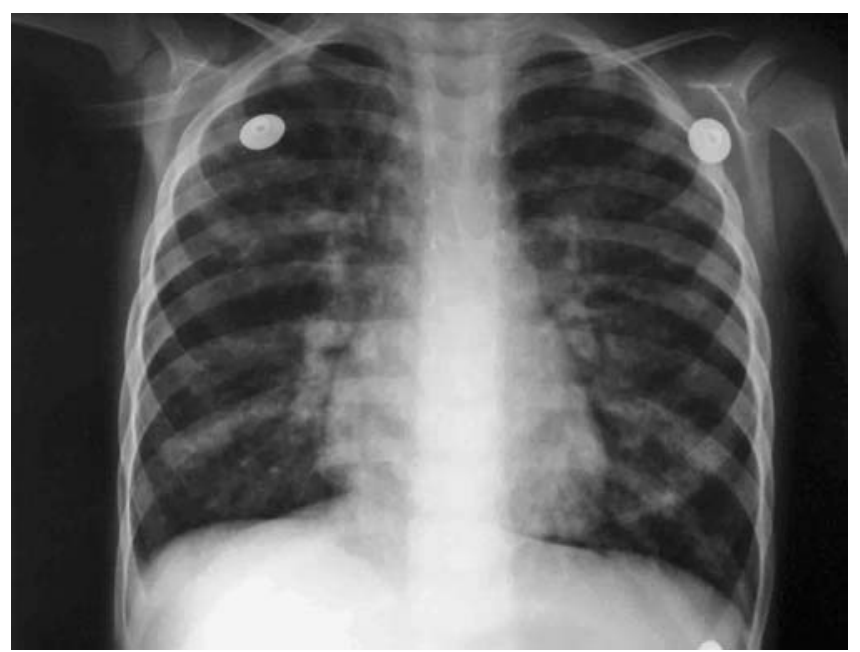

Fig. 1 Chest roentgenogram showing alveolar-interstitial pneumonitis with emphysema in both lung fields. A honeycomb appearance is seen, predominantly in the lower lung fields
Clubbing of the fingers and toes was also noted. Laboratory investigations revealed leukocytosis, with a white blood cell count of $29,400 / \mathrm{mm}^{3}(15 \%$ band cells, $47 \%$ segmented cells, and $20 \%$ lymphocytes). C-reactive protein was $1.81 \mathrm{mg} / \mathrm{dl}$. Liver and renal function tests were within normal limits. His arterial blood gas analysis showed hypercapnia and respiratory acidosis with compensatory metabolic alkalosis. He had hypochloremia with a chloride of $90 \mathrm{mEq} / 1$, sodium of $137 \mathrm{mEq} / \mathrm{l}$, and potassium of $4.0 \mathrm{mEq} / 1$. A chest roentgenogram showed pneumonitis with emphysema and a honeycomb appearance in both lower lung fields (Fig. 1). High-resolution computed tomography demonstrated multiple areas of focal bronchiectasis and sputum plugs in both lung cavities (Fig. 2). Respiratory failure with progressive hypercapnia and disturbance of the sensorium developed on the fourth hospital day,

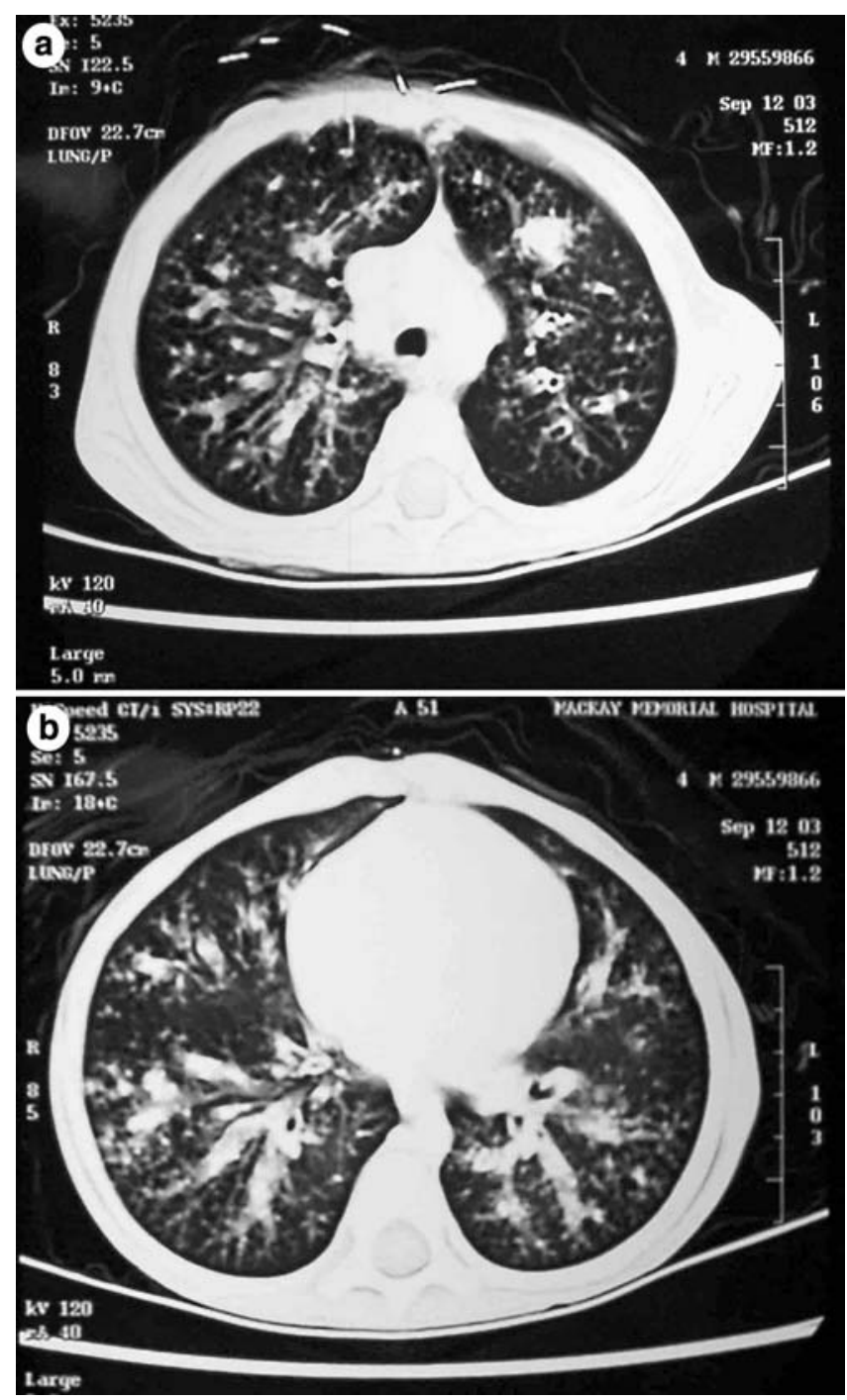

Fig. 2 High-resolution computed tomography of two different cuts (a, b) reveal dilated bronchioles extending to the peripheral lung field. Some sputum plugs are seen 
requiring intubation and assisted ventilation. The broad-spectrum antibiotics cefotaxime and erythromycin were prescribed after admission. His Mantoux test was negative. Three sets of gastric aspirates for tuberculosis were all negative. There was no evidence of aspergillosis or human immunodeficiency virus infection. The immunoglobulin (Ig) level and the IgG subclass levels were higher than normal (IgG 2,020 mg/dl, IgA $381 \mathrm{mg} / \mathrm{dl}$, IgM $176 \mathrm{mg} / \mathrm{dl}$, IgE $415 \mathrm{mg} / \mathrm{dl}$, IgG1 $1,476 \mathrm{mg} / \mathrm{dl}$, IgG2 $981 \mathrm{mg} / \mathrm{dl}$, IgG3 $172 \mathrm{mg} / \mathrm{dl}$, and IgG4 $58 \mathrm{mg} / \mathrm{dl}$ ), reflecting the chronic lung infection. The sputum culture grew Pseudomonas aeruginosa. Parenteral ceftazidime combined with aerosolized tobramycin and mucolytic agents were given to treat his complicated pulmonary infection. His respiratory condition gradually improved and he became afebrile after 4 days of antibiotic treatment. The antibiotics were continued for a total of 4 weeks until the pseudomonas was eradicated from the sputum.

The patient was also noted to have frequent, bulky, foul-smelling loose stools during hospitalization. A stool analysis was strongly positive for fat, and the trypsin activity was markedly decreased. Serum $\alpha 1$-antitrypsin was $3.1 \mathrm{~g} / \mathrm{l}$, slightly higher than normal. He was given a high calorie, high protein, low fat, and medium-chain triglyceride diet. Pancreatic enzymes and fat-soluble vitamins were given to treat his pancreatic insufficiency. The patient was discharged on day 35 with an improved pulmonary condition.

Cystic fibrosis seemed very likely according to his clinical and laboratory findings even though there was no family history of the disease. Because of the very low incidence of cystic fibrosis in Taiwan, pilocarpine sweat test laboratory facilities are not available. DNA analysis was undertaken by using an Elucigene CF29 kit, which is designed for rapid assay of 29 common CFTR mutations in Caucasian patients. A homozygous R553X mutation was detected, which was also confirmed by direct sequencing of the polymerase chain reaction (PCR) product, using the technique described in our previous paper (Cheng et al. 2005). This established the diagnosis of cystic fibrosis. His nonconsanguineous parents were subsequently both found to be R553X mutation carriers. The biparental origins of the R553X mutation were determined by quantitative fluorescent PCR (QF-PCR) using short tandem repeat polymorphic DNA markers specific for both the short arm and long arm of chromosome 7 (Table 1). The patient is currently

Table 1 Genotypic information of the proband, his sister, and parents at short tandem repeat (STR) markers specific for chromosome 7 obtained by fluorescent polymerase chain reaction (PCR) assays. Alleles (base-pair sizes) are listed below each individual

\begin{tabular}{llllll}
\hline STRs & Locus & Father & Mother & Sister & Patient \\
\hline D7S815 & 7p21.1 & 157,161 & 153,157 & 157,161 & 153,161 \\
D7S1824 & $7 q 34$ & 171,171 & 175,183 & 171,183 & 171,175 \\
D7S2423 & 7q36.3 & 231,239 & 229,237 & 229,239 & 231,237 \\
\hline
\end{tabular}

followed in our clinic where he receives intensive chest care and pancreatic enzyme replacement.

\section{Discussion}

Cystic fibrosis may result from any one of more than 1,000 different mutations in the CFTR gene (Jaffe and Bush 2001). The majorities of these mutations have been identified in European and North American populations and are exceedingly rare in Asians (Wagner et al. 1999). In the seven previously reported cases of cystic fibrosis in Taiwan, four novel null mutations were identified in four nonconsanguineous Taiwanese families by DNA analysis (Table 2). The $1898+5 \mathrm{G} \rightarrow \mathrm{T}$ mutation seems to occur only among east Asians (Zielenski et al. 1995; Suwanjutha et al. 1998). The R553X mutation accounts for $1.1 \%$ of cystic fibrosis chromosomes in Caucasian populations (Cheadle et al. 1992a, b), but it has never before been reported in a Taiwanese patient. Both parents of our patient were heterozygous for the R553X mutation. However, there was no known consanguinity within the parents' families. Both families were native to Taiwan, having been on the island for at least three generations. It is interesting to speculate on the origin of the R553X mutation in this family, as it most likely came from Westerners. The Dutch and Spanish colonized part of Taiwan more than 300 years ago for at least 30 years. It is possible that the mutation entered the gene pool through intermarriage. If this is the case, then it may be that the incidence of cystic fibrosis in Taiwan is underestimated. There may well be more Taiwanese with this or other CFTR gene mutations of Western origin.

The nonsense mutation R553X occurs in exon 11 of the CFTR gene and produces a truncated protein missing the regulatory domain, the second nucleotide binding fold, and the second transmembrane span, leading to a reduction or absence of cytoplasmic CFTR mRNA (Will et al. 1993). Most Caucasian patients who have the R553X mutation are heterozygous for it. Only two patients homozygous for R553X have been reported, one by Bal et al. (1991) and the other by Cheadle et al. (1992a, b). The first patient had failure to thrive beginning at the age of 16 months and had moderately compromised lung function until 13 years of age. The other patient was nearly asymptomatic and had no clubbing on examination at the age of 10 years. Both of these individuals had a later age of onset and relatively mild pulmonary involvement compared with patients heterozygous for the R553X mutation. Some published evidence suggests that stop codon mutations leading to a total absence of CFTR protein in airway cells may be less damaging than the presence of an altered protein (Cutting et al. 1990; Bal et al. 1991; Cheadle et al. 1992a, b; Will et al. 1993). This would explain the relatively mild clinical course in these two patients with a homozygous R553X mutation. However, our patient had 
Table 2 Cystic fibrosis transmembrane conductance regulator (CFTR) mutations and clinical manifestations in Taiwanese patients

\begin{tabular}{|c|c|c|c|c|c|}
\hline Patient (reference) & Gender & $\begin{array}{l}\text { Age at } \\
\text { diagnosis }\end{array}$ & Family history & $\begin{array}{l}\text { Diagnosis or } \\
\text { nucleotide } \\
\text { change }\end{array}$ & $\begin{array}{l}\text { Current clinical } \\
\text { conditions }\end{array}$ \\
\hline 2 (Wang et al. 1993) & Female & 9 months & $\begin{array}{l}\text { Older brother died at } \\
8 \text { months with } \\
\text { similar symptoms }\end{array}$ & Autopsy proved & Died at 16 months \\
\hline 4 (Zielenski et al. 1995) & Female & 8 years & Consanguineous marriage & $1898+5 \mathrm{G} \rightarrow \mathrm{T}$ & Died before 9 years \\
\hline $5(\mathrm{Wu}$ et al. 2000) & Male & 17 years & Sibling of patient 6 & $1898+5 \mathrm{G} \rightarrow \mathrm{T} / 2215 \mathrm{insG}$ & $\begin{array}{l}\text { Deteriorated pulmonary } \\
\text { function and renal } \\
\text { insufficiency }\end{array}$ \\
\hline 8 (Our patient) & Male & $\begin{array}{l}3 \text { years } \\
5 \text { months }\end{array}$ & No family history & R553X/R553X & $\begin{array}{l}\text { Chronic hypoxemia and } \\
\text { pancreatic insufficiency }\end{array}$ \\
\hline
\end{tabular}

failure to thrive beginning at the age of 2 months and developed severe chronic hypoxemia and pancreatic insufficiency at the early age of 3 years. His disease presented earlier and his condition deteriorated more rapidly than that of the two reported Caucasian patients with a similar genotype. Similar findings have also been noted in the seven other patients reported in Taiwan (Table 2) who had the onset of symptoms in infancy and died at an early age. One study in Pakistan also found that Asian patients with cystic fibrosis grew P. aeruginosa at an earlier age and had a more severe clinical course than did matched controls (Bowler et al. 1993). These findings suggest the gene expression may be different in Asian populations. Both genetic and environmental factors may be involved in this phenotypic disparity, which may be further confounded by underdiagnosis of the condition in Asia. An aggressive disease that leads to death at an early age may well escape diagnosis, especially if it is a disease that is assumed not to occur in this population.

If our speculation regarding the origin of the mutations in our patient's family is correct, the incidence of cystic fibrosis in Taiwan may in fact be higher than expected. Even with a genotype similar to that of Caucasians, the course of cystic fibrosis in Asians, particularly the early onset of pulmonary infection, appears to be much more severe. Earlier diagnosis and aggressive treatment are the only ways to improve the prognosis of Asian patients with this disease.

Acknowledgements The authors thank Peter M. George and Howard C. Potter, Canterbury Health Laboratories, Christchurch, New Zealand, for their technical assistance. We also thank Professor Lee-Jun Wong and Dr. Mary Jeanne Buttrey for critical review and valuable comments. This study was supported in part by research grant MMH-E-93004 from Mackay Memorial Hospital.

\section{References}

Ahn KM, Park HY, Lee JH, Lee MG, Kim JH, Kang IJ, Lee SI (2005) Cystic fibrosis in Korean children: a case report identified by a quantitative pilocarpine iontophoresis sweat test and genetic analysis. J Korean Med Sci 20:153-157

Alper OM, Shu SG, Lee MH, Wang BT, Lo SY, Lin KL, Chiu YL, Wong LJ (2003) Detection of Novel CFTR mutations in Taiwanese cystic fibrosis patients. J Formos Med Assoc 102:287-291

Anonymous (1976) Report of the Committee for a Study for Testing for Evaluation of Cystic Fibrosis. J Pediatr 88:711750

Bal J, Stuhrmann M, Schloesser M, Schmidtke J, Reiss J (1991) A cystic fibrosis patient homozygous for the nonsense mutation R553X. J Med Genet 28:715-717

Bowler IM, Estlin EJ, Littlewood JM (1993) Cystic fibrosis in Asians. Arch Dis Child 68:120-122

Cheadle J, al-Jader L, Goodchild M, Meredith AL (1992a) Mild pulmonary disease in a cystic fibrosis child homozygous for R553X. J Med Genet 29:597

Cheadle J, Myring J, al-Jader L, Meredith L (1992b) Mutation analysis of 184 cystic fibrosis families in Wales. J Med Genet 29:642-646

Cheng KS, Chen MR, Ruf N, Lin SP, Rutsch F (2005) Generalized arterial calcification of infancy: Different clinical courses in two affected siblings. Am J Med Genet A 136(2):210-213

Cutting G, Kasch L, Rosenstein B, Tsui L, Kazazian HJ, Antonarakis S (1990) Two patients with cystic fibrosis, nonsense mutations in each cystic fibrosis gene and mild pulmonary disease. N Engl J Med 323:1685-1689

Heim RA, Sugarman EA, Allitto BA (2001) Improved detection of cystic fibrosis mutations in the heterogeneous US population using an expanded, pan-ethnic mutation panel. Genet Med 3:168-176

Jaffe A, Bush A (2001) Cystic fibrosis: review of the decade. Monaldi Arch Chest Dis 56:240-247

Macek M Jr, Hamosh A, Kiesewetter S, McIntosh I, Rosenstein BJ, Cutting GR (1992) Identification of a novel nonsense mutation (L88X) in exon 3 of the cystic fibrosis transmembrane conductance regulator gene in a native Korean cystic fibrosis chromosome. Hum Mutat 1:501-502 
Morokawa N, Iizuka S, Tanano A, Katsube A, Muraji T, Eto Y, Yoshimura K (2000) Severe cystic fibrosis in a Japanese girl caused by two novel CFTR (ABCC7) gene mutations: M152R and 1540del10. Hum Mutat 15:485

Suwanjutha S, Huang NN, Wattanasirichaigoon D, Sura T, Harris A, Macek M Jr (1998) Case report of a Thai male cystic fibrosis patinet with the $1898+1 \mathrm{G} \rightarrow \mathrm{T}$ splicing mutation in the CFTR gene: a review of East Asian cases. Mutations in brief no. 196. Hum Mutat 12(5):361

Wagner JA, Vassilakis A, Yee K, Li M, Hurlock G, Krouse ME, Moss RB, Wine JJ (1999) Two novel mutations in a cystic fibrosis patient of Chinese origin. Hum Genet 104:511515

Wang JY, Hsieh KH, Chang MH, Chen SH, Lue HC (1987) Cystic fibrosis: report of a Chinese case with suggestive family history. J Formos Med Assoc 86:897-901

Wang MC, Shu SG, Chang SM, Ho WL, Chi CS (1993) Cystic fibrosis in two Chinese infants in Taiwan. Acta Paediatr Sin 34:314-321

Will K, Reiss J, Dean M, Schlosser M, Slomski R, Schmidtke J, Stuhrmann M (1993) CFTR transcripts are undetectable in lymphocytes and respiratory epithelial cells of a $\mathrm{CF}$ patient homozygous for the nonsense mutation R553X. J Med Genet 30:833-837
Wong LJ, Alper OM, Wang BT, Lee MH, Lo SY (2003) Two novel null mutations in a Taiwanese cystic fibrosis patient and a survey of East Asian CFTR mutations. Am J Med Genet 120A:296-298

Wright SW, Morton NE (1968) Genetic studies on cystic fibrosis in Hawaii. Am J Hum Genet 20:157-162

Wu CL, Shu SG, Zielenski J, Chiang CD, Tsui LC (2000) Novel cystic fibrosis mutation $\left(2215_{\text {INS G }}\right)$ in two adolescent Taiwanese siblings. J Formos Med Assoc 99:564-567

Yamashiro Y, Shimizu T, Oguchi S, Shioya T, Nagata S, Ohtsuka Y (1997) The estimated incidence of cystic fibrosis in Japan. J Pediatr Gastroenterol Nutr 24:544-547

Zielenski J, Markiewicz D, Lin SP, Huang FY, Yang-Feng TL, Tsui LC (1995) Skipping of exon 12 as a consequence of a point mutation $(1898+5 \mathrm{G} \rightarrow \mathrm{T})$ in the cystic fibrosis transmembrane conductance regulator gene found in a consanguineous Chinese family. Clin Genet 47:125-132 